\title{
POSSIBILITIES OF INCREASING TRANSMISSION CAPACITY OVERHEAD LINES
}

\author{
Michal ŠPES*, Lubomír BEŇA*, Miroslav MIKITA*, Michal MÁRTON**, Henryk WACHTA*** \\ ${ }^{*}$ Department of Electrical Power Engineering, Faculty of Electrical Engineering and Informatics, \\ Technical University of Košice, Mäsiarska 74, 04120 Košice, Slovak Republic, Tel.: +421 556023560 , \\ E-mail: michal.spes@tuke.sk, lubomir.bena@tuke.sk,miroslav.mikita@tuke.sk \\ ${ }^{* *}$ Department of Electronics and Multimedia Telecommunications, Faculty of Electrical Engineering and Informatics, Technical \\ University of Košice, Vysokoškolská 4, 04001 Košice, Slovak Republic, E-mail: michal.marton.3@student.tuke.sk \\ *** Department of Power Electronics, Power Engineering and Complex Systems, Faculty of Electrical and Computer Engineering, \\ Rzeszow University of Technology, W. Pola 2, 35-959 Rzeszow, Poland, Tel.: +48 17865 1977, email: hwachta@prz.edu.pl
}

\begin{abstract}
This article describes each option will increase transmission capacities of electrical power lines with an emphasis on the size of the transmitted power. The ampacity depends on electrical and mechanical properties of the conductor material, thermal insulation properties (the cables), ability to dissipate within the conductor generated and received from nearby heat and ambient weather conditions. Ambient conditions vary on the hydro meteorological impacts and local impacts. The hydro meteorological impacts include ambient temperature, wind speed and amount of sunlight radiation. Local impacts include location management and level of environmental pollution. At the core of the work is described in more detail these factors ambient conditions and the possibility of their calculation.
\end{abstract}

Keywords: overhead lines, transmission capacity, transmission ability, overhead line, ampacity

\section{INTRODUCTION}

Power lines are technological devices that transfer electrical power from primary sources or secondary sources to the point of consumption or to the consumer.

Power lines can be realized as overhead lines or as cable lines. In terms of implementation, they are preferred overhead lines. The main reasons are lower investment costs and lower operating costs. Another reason is simple maintenance of overhead lines.

We know these distributions systems in Slovak Republic:

Low voltage system: $0,4 \mathrm{kV}$

Medium voltage system: $6 \mathrm{kV} ; 10 \mathrm{kV} ; 22 \mathrm{kV} ; 35 \mathrm{kV}$

High voltage system: $110 \mathrm{kV}$

We know these transmissions systems in Slovak Republic:

High voltage system: $220 \mathrm{kV}$

Ultra-high voltage system: $400 \mathrm{kV}$

Extensive development of renewable sources requires expansion of transmission capacity of power lines. Despite the fact that power lines are an integral part of the system but their expansion is in seclusion interests.

For these reasons, it is necessary to seek other means of safeguarding the power transmission system. One possibility is operational methods which we monitor the temperature of the electrical wire and ambient influences. These indicate the current permissible current.

To determine the allowable current of the conductor is necessary to determine all factors influencing temperature of the conductor. Subsequent calculation can be determined at any given time under the conditions of maximum load capacity.

This method uses the current power lines and investment represents only the cost of computing software.

Congestion problems of power lines appeared with massive development of renewable sources of high output. We mean solar and wind power plants if we talk about renewable sources [1] [2]. They are often connected to one end of the power system. Electric power that they supply is often necessary to transfer over long distances. This leads to overload of local power system [2].

The construction of new transmission lines has been in the past and at present is due to timetable and also a commitment to a huge problem.

- The problem of financing the construction of new lines

- The massive construction of renewable energy sources without respecting energy studies

- Contradiction environmental activists

The problem of the low capacity transmission lines are beginning to be observed not only in emergency situations but also in the normal operation [3].

Size of the transmitted power is defined as follows:

$S=U \cdot I$

Where:

$S$ - Apparent Power

$U$ - RMS Voltage

$I$ - RMS Current

Thus, the size of the transmitted power can be increased by changing the size of the current, voltage, or both parameters simultaneously.

Methods for increasing the transmission capacity:

- Increase ampacity

- Operational modalities

- Methods of increasing voltage

- Extensive solutions [3]

\section{INCREASE AMPACITY}

Ampacity is the maximum current that can flow through the conductor, without the damage in the short or long term [4]. 
This current is primarily derived from the maximum permissible temperature, the determination of which varies depending on ambient conditions, particularly then at ambient temperature and the speed and wind direction [4].

Ampacity is thus dependent on these factors:

- Electrical and mechanical properties of the conductor material

- Thermal insulation properties of the material in conductor

- The thermal capacity and conductivity of the guide body and its ability to transfer heat to the surroundings

- Environmental conditions

Conductor temperature also affects the size of the ampacity because it prolongs the wires and bring them closer to the ground and increase resistivity [5].

Since the sag depends on the temperature and is difficult to measure, it focuses research on the possibility of detecting the temperature of the conductors from which it then derives sag. Due to the quadratic dependence of temperature on the size of the amount of current flowing through you can make a general idea about the differences Ampacity as shown in Fig. 1, when the conductor 400 $\mathrm{mm}^{2}$ increase permissible operating temperature of $10{ }^{\circ} \mathrm{C}$ means an increase Ampacity of about 50 to 100 A. For most prevalent the conductors ACSR this temperature increase means a change sag of 10-15 cm [5].

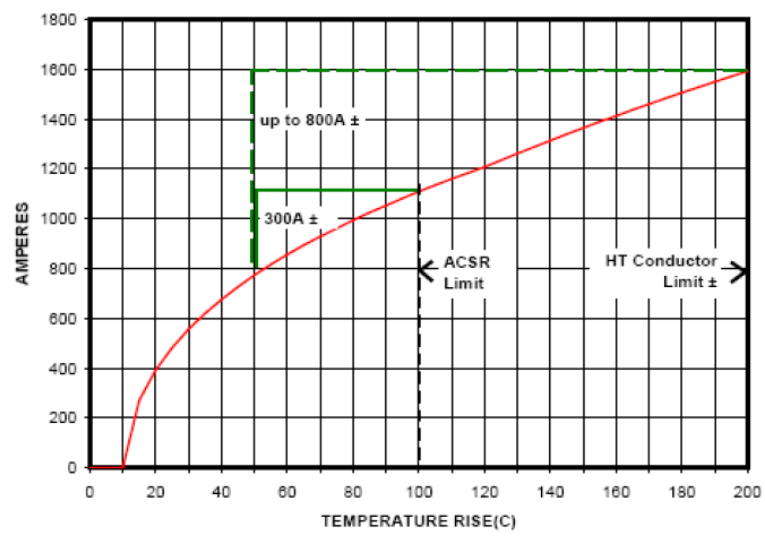

Fig. 1 The dependence of the capacity on the temperature conductors [5]

\subsection{The methods depend on the conductors}

The first option to increase ampacity is provided maintaining conductors. This method consists in increasing the maximum permissible operating

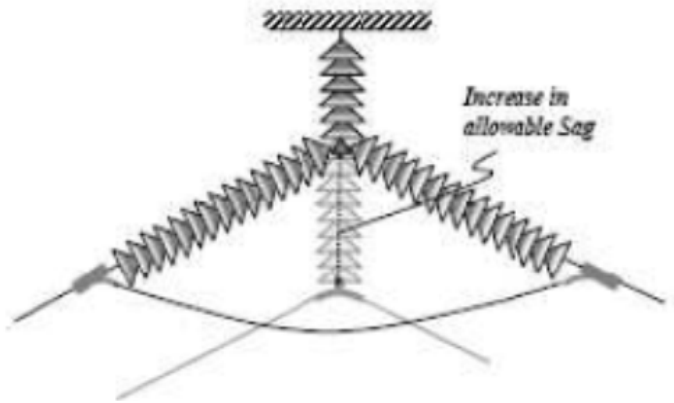

Fig. 2 Replacement of insulators used to increase the height of wires above ground temperature. The most older foreign power lines were rated for an operating temperature of $50^{\circ} \mathrm{C}$. The maximum allowable operating temperature of the conductor ACSR is $90-100^{\circ} \mathrm{C}$. With this method it is necessary to take into account the increase sag. Therefore, it is necessary to exchange and shortening of the insulator [6] [17].

The second option is replacement conductors. This is an option when the conductors are not adequately dimensioned with respect to the standard. Where we have a reserve in the load bearing structures for the conductors of larger cross section. Despite the high prices occurs to extend the life of power lines. When using a high temperature conductors ampacity can be increased by up to $100 \%$. Of course it is necessary to reckon with the fact that with an increase in temperature of aluminum, increases own resistivity. Among other things, occurring also further the warming due to reactive losses [7] [8] [9] [12].

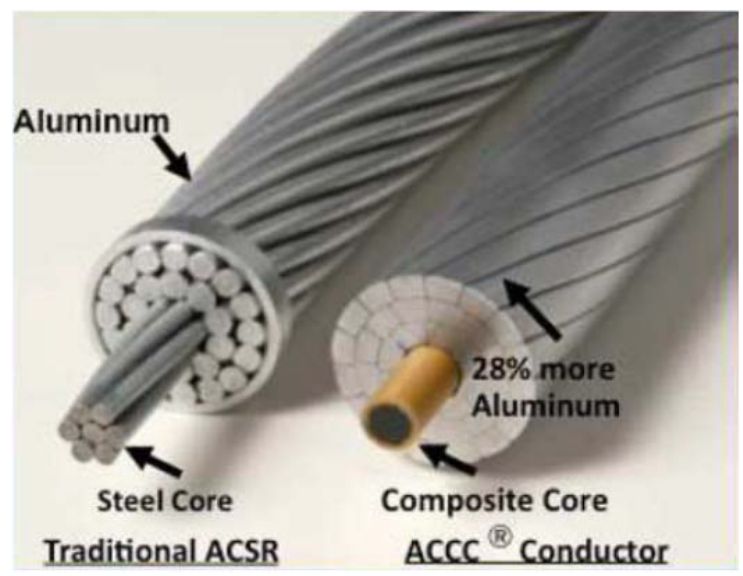

Fig. 3 Comparison of the structure the conductors ACSR and ACCC [9]

\section{OPERATIONAL MODALITIES}

This solution consists in the expression of the actual temperature of the electrical conductor and the full exploitation towards the real limits that vary depending on environmental conditions. These are mainly on flow velocity of wind and ambient temperature [10].

Proposal for a new power line is in accordance with standards designed to be safe transmission of electricity even under the worst operating conditions. For these reasons, the management of such capacity is not used [10].

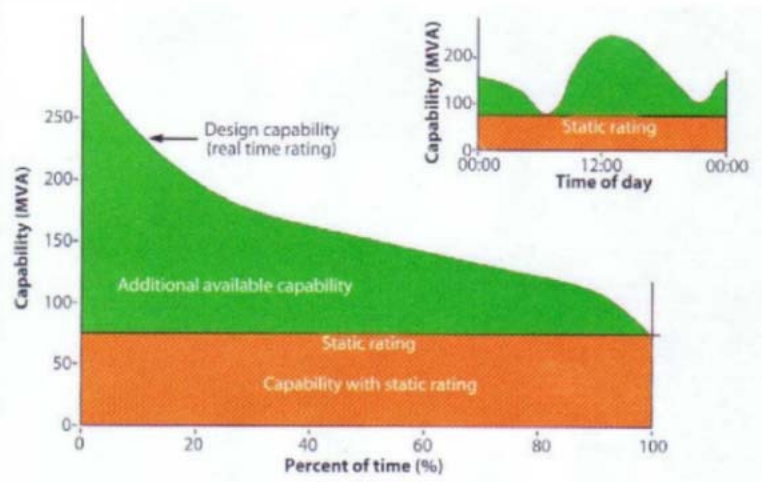

Fig. 4 Static characteristics ampacity for a period of time [10] 


\subsection{Probabilistic methods}

Their principle consists in applying probabilistic models weather conditions in different periods and locations in determining the load limit. The criterion is not the temperature but the maximum allowable sag [11].

We know these probabilities methods:

- The method of crossing the projected temperature

- Determining the absolute probability of failure

- Simulation Methods estimated of security

\subsection{Real-time monitoring}

Measurement of various quantities related to the current state of the conductors is carried out due to time optimization of Ampacity under given ambient conditions, especially temperature measurements or sag. With knowledge of the current state of the line, operators can improve planning and management during accidents and emergency situations [11].

That the measurement data used effectively must be immediately after measuring analyze, safely and in time to send to the control center and moreover operators interpret as meaningful information for them, such as e.g. instantaneous reserve.

\subsection{The temperature measurement of conductors}

Use direct measurement using the measurement systems directly mounted on wire lines at selected locations (local) Fig. 5, or laying the optical fiber directly to the conductors (global) Fig. 6, which allows you to monitor the temperature profile of about every meter up to a distance of several dozen kilometers [19].

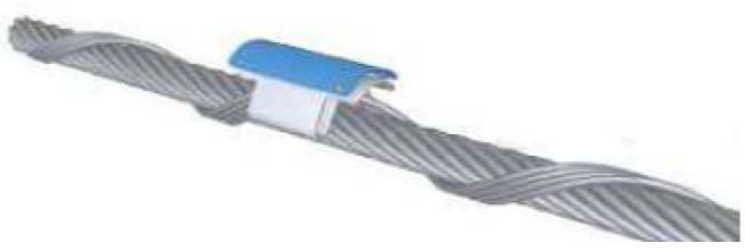

Fig. 5 RIBE-Ritherm system [19]

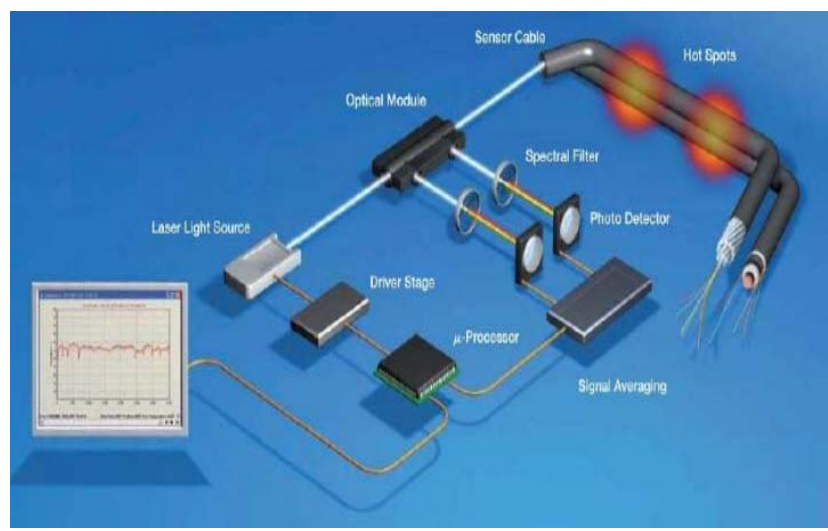

Fig. 6 VALCAP system [19]

\subsection{Measurement of mechanical tension}

The size of mechanical tension derives from the tension of conductors between the poles and indirectly determines the sag in that section. Sensors are placed between the grounded end of the insulator and an anchor point on the pole [12].

\section{METHODS OF INCREASING VOLTAGE}

If the design of poles permits, it is very advantageous to increase the line voltage, and thereby at the same transmit power quadratically reduce losses [16].

With the transition to a higher voltage is beyond an exchange of insulating elements and switching devices are often connected also total replacement of conductors due to the emergence of the corona [16].

A further disadvantages may constitute line redundancy in the voltage level and need long time for reconstruction. Also, problems may arise with height above the ground, which demands with a higher level of voltage is also rising [16].

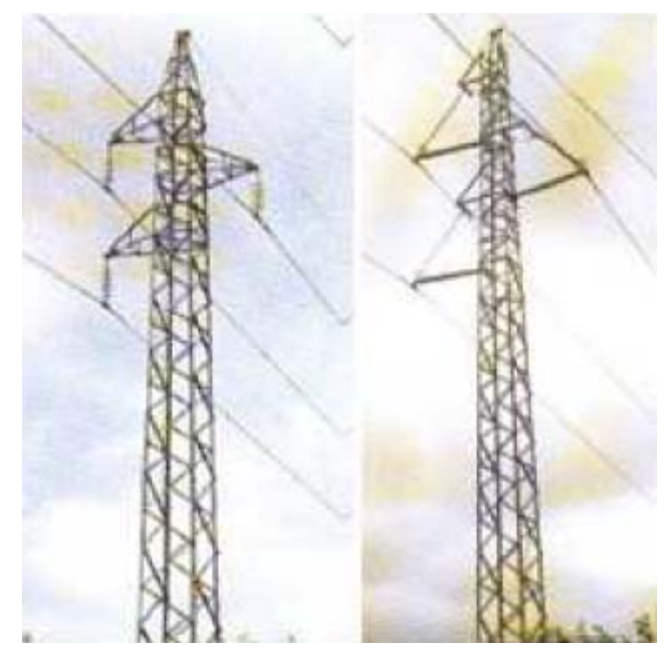

Fig. 7 Changing the line voltage from $66 \mathrm{kV}$ to $220 \mathrm{kV}$

\section{POWERLINE AMPACITY SYSTEM}

Conductor ampacity is defined as the maximum permissible load current, which can transmit the conductor without compromising its function. This distortion is mainly caused by exceeding the maximum permissible temperature.

The maximum current that can be transferred over the line, is not a constant value as yet, but is determined for the unsurpassable temperature conductors depending on ambient conditions - particularly ambient temperature and wind flow.

The ampacity depends on:

- Electrical and mechanical properties of the conductor material

- Thermal insulation properties (the cables)

- Ability to dissipate within the conductor generated and received from nearby heat

- Ambient weather conditions 
It is therefore apparent that the ampacity is mainly influenced by the thermal condition of the conductors, because it determines the extension conductors and therefore sag power line over the terrain.

In determining the maximum transmission capacity we use a method that is based from thermal equilibrium between the conductors and the environment.

At steady state, this equation can be expressed as equality heat gain $=$ heat loss [4].

The full form of the equation is:

$P_{J}+P_{M}+P_{S}+P_{i}=P_{C}+P_{r}+P_{W}$

Where:

$P_{J}(\mathrm{~W})$ - heat losses in the conductor,

$P_{M}(\mathrm{~W})$ - magnetic heating of magnetic field variations $\mathrm{AC}$,

$P_{S}(\mathrm{~W})$ - solar radiation,

$P_{i}(\mathrm{~W})$ - heating from the corona,

$P_{C}(\mathrm{~W})$ - cooling by heat convection - by radiation,

$P_{r}(\mathrm{~W})$ - radiant cooling,

$P_{W}(\mathrm{~W})$ - cooling from water evaporation.

Heating corona $P_{i}$, cooling by evaporation of water $P_{W}$ and heating by changing the magnetic field of alternating current $P_{M}$ in the equation is usually neglected, from which we get the final equation [4] [15] [18].

$P_{J}+P_{S}=P_{C}+P_{r}$

In determining the maximum transmission capacity using methods that based conductor of heat balance and its surroundings. By entering the ambient temperature, the geographic position line (to determine the solar radiation), wind direction and velocity. The parameters for calculating the predicted properties of the cables - ability to absorb sunlight and heat transfer coefficient on the surface of the conductor [13] [14].

At steady state must balance energy increases the temperature of the conductor and the amount of energy to dissipate heat from the conductor:

$q_{S}+R \cdot I^{2}=q_{C}+q_{r}$

Where:

$q_{S}\left(\mathrm{~W} \cdot \mathrm{m}^{-1}\right)$ - energy from solar radiation, $q_{C}\left(\mathrm{~W} . \mathrm{m}^{-1}\right)$ - energy heat transfer from the conductor to the surroundings, $q_{r}\left(\mathrm{~W} . \mathrm{m}^{-1}\right)$ - energy from heat radiation.

From the foregoing equation can be derived a formula for calculating the current:

$$
I=\sqrt{\frac{q_{C}+q_{r}-q_{S}}{R_{t}}}
$$

Where $R_{t}$ is conductor resistance at known temperature.

\subsection{Energy from solar radiation}

Heat gain supplied by sunlight depends on the efficient transfer surface conductor and the fact that corroded and dirty conductor can absorb around $90 \%$ of radiation compared with a perfectly black body than newly placed conductor on poles whose absorption is between $20-30 \%$ [4].

We can determine heat gain supplied by sunlight as follows:

$q_{S}=\alpha \cdot Q_{S} \cdot \sin (\Theta) \cdot A^{\prime}$

Where:

$\alpha(-)$ is the thermal coefficient of resistance of the conductor material,

$Q_{S}\left(\mathrm{~W} . \mathrm{m}^{-2}\right)$ is solar heat,

$A^{\prime}(\mathrm{m})$ is diameter of the conductor,

$\Theta$ is the angle of incidence of solar radiation.

\subsection{Energy heat transfer from the conductor to the surroundings}

Cooling fluid flow is physically intricate plot depending on the nature of hydrodynamic and thermal boundary layer, the shape and the size is determined by the speed and the direction of flow, formed in the close proximity to the heat transfer surface and on mass quantities of fluid, such as density, kinematic viscosity, thermal conductivity and isobaric specific heat in the event that no change of state of the fluid [4].

Mathematical expression is thus very complicated and without major simplification almost impossible. For ease of calculation may be used to simplify the equation, it is not necessary to find the appropriate criterion values in the tables, but substituting direct measurements of wind flow to the appropriate body - conductor [4].

$$
\begin{aligned}
& q_{C}=\left[1,01+0,0372 \cdot\left(\frac{D \cdot \rho_{f} \cdot V_{W}}{\mu_{f}}\right)^{0,52}\right] \\
& k_{f} \cdot K_{\text {angle }} \cdot\left(T_{C}-T_{a}\right)
\end{aligned}
$$

Where:

$D(\mathrm{~mm})$ is diameter of conductor,

$\rho_{f}\left(\Omega \cdot \mathrm{mm}^{-2}\right)$ is density of air,

$V_{W}\left(\mathrm{~m} . \mathrm{s}^{-1}\right)$ is wind speed,

$\mu_{f}$ (Pa.s) is dynamic viscosity of air,

$k_{f}\left(\mathrm{~W} . \mathrm{m}^{-1} \cdot{ }^{\circ} \mathrm{C}^{-1}\right)$ is the thermal conductivity of air,

$K_{\text {angle }}(-)$ is factor angle wind conditions,

$T_{C}\left({ }^{\circ} \mathrm{C}\right)$ is conductor temperature,

$T_{a}\left({ }^{\circ} \mathrm{C}\right)$ is ambient temperature.

\subsection{Energy from heat radiation}

When a bare overhead conductor is heated above the temperature of its surroundings, energy is transmitted by radiation to the surroundings. The rate at which the energy is radiated is dependent primarily on the difference in temperature between the conductor and its surroundings, which are assumed to be at ambient temperature. The surface condition of the conductor, its emissivity, also 
affects the radiative heat transfer. Radiation is described by the Stefan-Boltzmann law, relating the radiative energy transmission to the difference between the conductor surface temperature and the surrounding temperature, expressed in absolute (Kelvin) degrees to the fourth power. The constants in Equations (8) include the Stefan Boltzmann constant and conversion factors to produce a result in the desired units [4].

$$
q_{r}=0,0178 \cdot D \cdot \varepsilon \cdot\left[\begin{array}{l}
\left(\frac{T_{C}+273}{100}\right)^{4} \\
-\left(\frac{T_{a}-273}{100}\right)^{4}
\end{array}\right]
$$

Where $D(\mathrm{~m})$ is conductor diameter, $\varepsilon(-)$ is emissivity factor.

\section{CONCLUSIONS}

This article deals with increasing the transmission capabilities of lines and maximum of the current capacity of conductors.

As is known, demands for electricity transmission are rising mainly due to the deployment of renewable energy sources. Electricity system was adapted to centralized sources of electricity whereas renewable sources of electricity fall within the decentralized sources. The second negative impact is bad prediction of the amount of electricity generated. In the event of a bad estimation of the amount of energy produced there is a problem overloading lines and their subsequent failure that could result in the disintegration of the electricity grid. For these reasons, is urgent need for construction of new power lines. The construction itself is time consuming and costly, which represents an investment for a considerably longer period.

For these reasons it is how to maximize the use of existing power lines or increase of the current capacity of the conductors which results also proportionately increase the operational safety of the electricity system.

\section{REFERENCES}

[1] PIERNOT, S. J. - LEAHY, J.: Maximize the capacity of your transmission lines, Transmission and Distribution Conference and Exposition, IEEE/PES, Atlanta, GA, Vol. 1, pp. 391-396, 2001.

[2] THE ALUMINUM ASSOCIATON - Aluminum Electrical Conductor Handbook, 2nd ed. Washington, DC, 1982.

[3] WORKING GROUP B2.12.: Guide for selection of weather parameters for bare overhead conductor rating, CIGRE, 2006.

[4] IEEE POWER ENGINEERING SOCIETY: IEEE standard for calculating the current temperature of bare overhead conductors, 2007.

[5] BRACALE, A. - ANDREOTTI,A. - CARPINELLI, G. - DE MARTINIS, U.: Probabilistic index for increasing hourly transmission line rating, International Journal of Emerging Electric Power Systems, Vol. 8, Iss. 4, 2007.

[6] CARRERAS, B. B.: Evidence for self-organized criticality in a time series of electric power system blackouts, IEEE Transaction on Circuits and Systems - I: REGULAR PAPERS, Vol. 51, No. 9, 2004.

[7] CIGRE TASK FORCE B2.12.3.: Sag-tension Calculation Methods for Overhead Lines, Technical Brochure 324, 2007.

[8] CIGRE WORKING GROUP B2.12.: Alternating Current (AC) Resistance of Helically Stranded Conductors, Technical Brochure 345, 2008.

[9] CIGRE WORKING GROUP B2.12.: Thermal Behaviour of Overhead Conductors, Technical Brochure 207, 2002.

[10] Overhead Conductor Manual, 2nd Edition, Southwire, 2007.

[11] KIESSLING, F. - NEFZGER, P. - NOLASCO, J. F. - KAINTZYK, U.: Overhead Power Lines Planning, Design, Construction, Springer-Verlag Berlin Heidelberg, ISSN 978-3-642-97879-1, 2003.

[12] MIDAL CABLES: Thermal Resistant Aluminium Conductor Aluminium Clad Steel Reinforced, [online], Kingdom of Bahrain.https://www.midalcabl e.com/tacsr-thermal-resistant-aluminum-alloyconductors-steel-reinforced

[13] MORGAN, V. T. - FINDLAY, R. D.: Effects of Axial Tension and Reduced Air Pressure on the Radial Thermal Conductivity of a Stranded Conductor, IEEE Transactions on Power Delivery, Vol. 8, No. 2, pp. 553-558, 1993.

[14] WONG, T. Y. - FINDLAY, J. A. - MCMURTIE, A. N.: An On-Line Method for Transmission Ampacity Evaluation, IEEE Transactions on Power Apparatus and Systems, Vol. PAS-101, No. 2, 1982.

[15] DEB, A. K.: Object oriented expert system estimates line ampacity, IEEE Computer Applications in Power, Vol. 8, No. 3, pp. 30-35, 1995.

[16] FU, J. - MORROW, D. J. - ABDELKADER, S. FOX, B.: Impact of Dynamic Line Rating on Power Systems, Universities' Power Engineering Conference (UPEC), Proceedings of 2011 46th International, Soest, Germany, pp. 1-5, 2011.

[17] BALANGÓ, D. - NÉMETH, B. - GOCSEI, G.: Predicting conductor sag of power lines in a new model of Dynamic Line Rating, IEEE Electrical Insulation Conference (EIC), Seattle, WA, pp. 41-44, 2015.

[18] WIJETHUNGA, A.H. - WIJAYAKULASOORIYA, J. V. - EKANAYAKE, J. B.: Effect of sampling rate of weather parameters on the dynamic line rating, Industrial Instrumentation and Control (ICIC), pp. 663-668, 2015. 
[19] NKT CABLES: Optical phase conductors (OPGW/OPPC), (Optické fázové vodiče (OPGW/OP PC)), Czech Republic. http://www.nktcables.com/cz/solutions/electricaloinfrastructure

Received June 26, 2016, accepted September 15, 2016

\section{BIOGRAPHIES}

Michal Špes was born in 1991. In 2015 graduated (MSc) at the Department of Electrical Power Engineering on the Faculty of Electrical Engineering and Informatics at Technical University of Košice. At present is a Ph.D. student in the Department of Electrical Power Engineering on the Faculty of Electrical Engineering and Informatics at Technical University of Košice. He received a master degree in electric power engineering on subject evaluation of generator exciting outage. His scientific research is mainly focused on research of powerline ampacity system.

Lubomír Beňa was born in 1975 in Bardejov, Slovakia. In 1998 he graduated (MSc.) at the Department of Electrical Power Engineering, Faculty of Electrical Engineering and Informatics, Technical University of Košice. He defended his $\mathrm{PhD}$. in the field of overhead power lines mechanics in 2001. Since 2010 he is associated professor at the Department of Electrical Power Engineering. His scientific research is analysis of electrical power systems and optimization problems in electrical power engineering.
Miroslav Mikita is a Ph.D. student in the Department of Electrical Power Engineering on the Faculty of Electrical Engineering and Informatics at Technical University of Košice. He received a master degree in electric power engineering on subject designing of pumped hydroelectric power plant. His scientific research is mainly focused on research of renewable sources cooperation.

Michal Márton was born in 1992. In 2016 graduated (MSc) at the Department of Electronics and Multimedia telecommunications. At present is a Ph.D. student in the Department of Electronics and Multimedia Telecommunications on the Faculty of Electrical Engineering and Informatics at Technical University of Košice. He received a master degree in multimedia telecommunications on measurement with the fibre optic gyroscope system. His scientific research is mainly focused on research of optical communications.

Henryk Wachta was born in 1964 in Przemysl, Poland. In 1993 he graduated (MSc.) at the Department of Power Electronics and Power Engineering, Faculty of Electrical and Computer Engineering, Rzeszow University of Technology. He defended his PhD. in the field of lighting technology in 2004 at the Warsaw University of Technology. Since 2004 he is lecturer at the Department of Power Electronics, Power Engineering and Complex Systems at the Rzeszow University of Technology. His scientific research is construction of luminaires and luminaires work in the electrical installation. 